\title{
Polymorphisms in interleukin genes and their association with the risk of recurrent pregnancy loss
}

\author{
Ting Wang ${ }^{1}, \mathrm{Na} \mathrm{Lu}{ }^{1}$, Yajie $\mathrm{Cui}^{2}$ and $\mathrm{Li} \operatorname{Tian}^{1 *}$ \\ ${ }^{1}$ Center for Assisted Reproductive Technology, Northwest Women's and Children's Hospital, No. 1616, \\ Yanxiang Road, Xi'an, Shaanxi 710061, China \\ ${ }^{2}$ Department of Gynaecology and Obstetrics, Xi'an Fourth Hospital, No. 21, Jiefang Road, \\ Xi'an, Shaanxi 710004, China
}

(Received 21 October 2018, accepted 11 February 2019; J-STAGE Advance published date: 3 July 2019)

Interleukins play important roles in pregnancy. Altered expression and splicing of various interleukins have been linked to the pathophysiology of recurrent pregnancy loss. Polymorphisms in interleukin genes can affect the expression and/or splicing of their respective genes and thus influence the risk of recurrent pregnancy loss. In this work, we examined the association between the $I L 1 B$ rs16944, IL1B rs1143634, IL6 rs1800795, IL6 rs1800796, IL10 rs1800896 and IL18 rs187238 polymorphisms and recurrent pregnancy loss risk in a Chinese population. Study subjects comprised 598 idiopathic recurrent pregnancy loss patients and 603 controls. The genotyping was accomplished by PCR-RFLP. Regression analysis was performed to evaluate the disease association. After adjustment by Bonferroni correction, only the $I L 1 B$ rs16944 and IL6 rs1800796 polymorphisms were significantly associated with risk of recurrent pregnancy loss. The heterozygous TC genotype of $I L 1 B$ rs16944 had an adjusted odds ratio (aOR) of 1.4209 (1.1302-1.8929) $(P=0.0019)$, while the homozygous $C C$ genotype had an aOR of $1.7398(1.2133-2.3203)(P=0.0008)$. A significant association was also observed for the $\mathrm{C}$ allele $[\mathrm{aOR}=1.3747(1.1296-1.8972)](P=0.0003)$. For IL6 rs1800796, the heterozygous CG genotype, the homozygous GG genotype and the G allele had aORs of $0.7342(0.4412-0.8423)(P=0.0016), 0.5424(0.1768-0.7865)(P=$ $0.0014)$ and $0.7009(0.4511-0.8034)(P=0.0007)$, respectively. In summary, the $I L 1 B$ rs16944 and IL6 rs1800796 variants were associated with an increased and a decreased recurrent pregnancy loss risk, respectively.

Key words: recurrent pregnancy loss, association, genetic polymorphisms, odds ratio

\section{INTRODUCTION}

Recurrent pregnancy loss refers to repeated and consecutive ( $\geq 3$ times) spontaneous abortion events that occur before the 20th gestational week of pregnancy. This condition causes substantial emotional stress to the patient and her family. It is estimated that as many as $1-2 \%$ of healthy women experience recurrent pregnancy loss (Diejomaoh, 2015). Several factors are known to contribute to this condition, such as advanced maternal age, abnormalities of the uterus and endocrine diseases (Garrido-Gimenez and Alijotas-Reig, 2015). However, these factors can only explain the etiology of the condition in a small subset of patients. Up to $60 \%$ of recur-

\footnotetext{
Edited by Atsushi Tajima

* Corresponding author. E-mail: tularkovu@yahoo.com DOI: http://doi.org/10.1266/ggs.18-00051
}

rent pregnancy losses have an unknown or unexplained cause, and represent a major challenge in reproductive medicine (Diejomaoh, 2015).

Genetic polymorphisms may be at least partially responsible for the incidence of these unexplained recurrent pregnancy losses (Daher et al., 2012). Cytokines, particularly interleukins, are important mediators in many reproductive events (Prins et al., 2012; Cheng and Sharma, 2015; Southcombe et al., 2015). IL-1B, for example, is crucial for the regulation of immune responsiveness of Th1/Th2 cells, which is necessary for a successful pregnancy (Agrawal et al., 2012; Sykes et al., 2012). IL-6 is involved in the modulation of embryonic implantation and placental development (Prins et al., 2012). IL-10 actively suppresses the maternal immune system to avoid rejection of the fetal allograft (Thaxton and Sharma, 2010; Cheng and Sharma, 2015). On the other hand, IL-18 may stimulate the production of 
interferon-gamma, which is needed for the remodeling of the blood vessels during pregnancy (Weissenbacher et al., 2014). Given the importance of these interleukins in pregnancy, a number of studies have investigated the association between polymorphisms in interleukin genes and the risk of recurrent pregnancy loss. Although the results obtained are often contradictory, the studies do provide some indications that functional polymorphisms, which are known to influence the expression of their respective genes, can influence the risk of recurrent pregnancy loss (Daher et al., 2012).

Among the most commonly studied interleukin polymorphisms with regard to their relationship with recurrent pregnancy loss risk are the $I L 1 B$ rs16944, IL1B rs1143634, IL6 rs1800795, IL6 rs1800796, IL10 rs1800896 and IL18 rs187238 polymorphisms (meta-analyzed in Agrawal et al., 2012; Chen et al., 2015; Lee et al., 2015; Woods et al., 2015; Su et al., 2016). Except for IL1B rs1143634, all other polymorphisms occur in the promoter regions of their genes and are thought to affect the rate of gene transcription. On the other hand, IL1B rs1143634 is predicted to disrupt the splicing process (Woods et al., 2015), which can then influence the normal function of IL-1B and, as a result, the risk of recurrent pregnancy loss. The association of these polymorphisms has been investigated in several populations, but few studies have been conducted in the Chinese population (Agrawal et al., 2012; Chen et al., 2015; Lee et al., 2015; Woods et al., 2015; Su et al., 2016).

For the $I L 1 B$ rs16944 polymorphism, two studies have demonstrated an association between the variant allele and the risk of recurrent pregnancy loss in a Korean population (Kim et al., 2014) and a Chinese population (Ma et al., 2017). However, another study conducted in China showed a lack of association, which indicates that the effect of the polymorphism differs even among distinct geographical areas of the same population (Ma et al., 2012). In addition, a study from the UK also failed to find an association between the polymorphism and risk of recurrent pregnancy loss (Linjawi et al., 2005). Besides, the association of the $I L 1 B$ rs1143634 polymorphism and recurrent pregnancy loss risk has been investigated in two populations in China (Ma et al., 2012, 2017). No significant association was found in either report. Nevertheless, no study has yet been conducted on these two IL1B polymorphisms in the northwestern part of China.

Similarly, for IL6 rs1800795 and rs1800796 polymorphisms, contradictory findings have been observed in several reports. For the former, Demirturk et al. (2014) and Parveen et al. (2013) demonstrated an association of the polymorphism with risk of recurrent pregnancy loss in Turkish and northern Indian populations, respectively. However, no significant association was found in Saudi Arabian (Alkhuriji et al., 2013), Iranian (Bahadori et al., 2014) or Romanian populations (Bohiltea and
Radoi, 2014). In eastern China, Ma et al. (2017) also found no significant association of the polymorphism with recurrent pregnancy loss. The effect of the polymorphism in northwestern China remains unknown. On the other hand, for rs1800796, a few studies have reported a significant association with recurrent pregnancy loss (Karhukorpi et al., 2001; Qaddourah et al., 2014; Ma et al., 2017), although there is also one study that found no significant association (Alkhuriji et al., 2013).

IL10 rs1800896 is another commonly studied polymorphism in recurrent pregnancy loss. Previous work has shown a positive link between this polymorphism and the condition in several populations (Parveen et al., 2013; Bahadori et al., 2014), but contradictory findings were again noted in other populations (Karhukorpi et al., 2001; Kamali-Sarvestani et al., 2005; Alkhuriji et al., 2013; Qaddourah et al., 2014; Ma et al., 2017). Likewise, for the IL18 rs187238 polymorphism, two studies demonstrated an association between the variant allele and risk of recurrent pregnancy loss (Wang et al., 2014; Yue et al., 2015), but others failed to find a significant association (Ostojić et al., 2007; Al-Khateeb et al., 2011; Messaoudi et al., 2012). These inconsistent results show that the role of the polymorphisms in recurrent pregnancy loss differs from population to population. Because the effect of these polymorphisms on Han Chinese from northwestern China remains unknown, the current study aimed to investigate the association of $I L 1 B$ rs16944, IL1B rs1143634, IL6 rs1800795, IL6 rs1800796, IL10 rs1800896 and IL18 rs187238 polymorphisms with the risk of recurrent pregnancy loss among Han Chinese in Shaanxi, China.

\section{MATERIALS AND METHODS}

Sample size The sample size required for this study was calculated using the Quanto program by considering the probability of exposure in both cases and controls, the difference between which was set at $7.73 \%$ based on our preliminary (unpublished) investigation. To achieve a study power of 0.9 , a minimum of 603 cases and 603 controls was required. We enrolled these numbers into the study, but five cases withdrew before the completion of the research. Because of this, the final number of subjects recruited was 598 cases and 603 controls. This yielded a study power of 0.896 , which is still sufficiently large for the analysis. Written informed consent was obtained from the subjects before they participated in the study. The study was conducted with approval from the Northwest Women's and Children's Hospital (approval no: 00345981231) and Xi'an Fourth Hospital (approval no: 0000001298173-AKK), Xi'an, Shaanxi, China.

Inclusion and exclusion criteria To be included in the study, cases must have experienced three or more occurrences of unexplained pregnancy loss before the 20th ges- 
tational week. Cases with known causes of pregnancy loss were excluded from the study. For controls, the inclusion criterion was having had a minimum of three successful live births. Controls with a history of spontaneous abortions or preterm birth were excluded. All subjects were Han Chinese and were recruited from Xi'an, Shaanxi province between December 2014 and November 2017.

Genetic analysis All polymorphisms were genotyped with PCR-RFLP. PCR was performed with Taq PCR MasterMix (TIANgen, China) and the primers used are listed in Table 1. Following PCR, the amplicons were digested with restriction enzymes (Table 2 ) at $37{ }^{\circ} \mathrm{C}$ overnight. All restriction enzymes were purchased from New England Biolabs (USA). Next, the digested fragments were electrophoresed on a $2 \%$ agarose gel. The electrophoresis bands were stained with ethidium bromide and visualized on a UV transilluminator to identify the genotype of the polymorphisms based on their sizes (Table 2).

Statistical analysis Statistical analysis was performed with IBM SPSS. A chi-squared test was used to compare categorical variables between the subjects, and a $t$-test was used to compare numerical variables. A goodness-of-fit test was used to examine deviation of the polymorphisms from Hardy-Weinberg equilibrium. A $P$ value of $<0.05$ was considered significant for the above analyses. Logistic regression was used to calculate the odds ratio (OR) for determining the association between the polymorphisms and the risk of recurrent pregnancy loss. The major (wild-type) alleles and genotypes were chosen as the references in this analysis. The OR was adjusted for age, smoking habits and alcohol consumption habits of the subjects. Since we examined six polymorphisms in this study, multiple comparisons error was corrected with the Bonferroni correction. For this reason, a $P$ value of $<0.008$ was considered significant for the

Table 1. PCR primers used for amplification of DNA

\begin{tabular}{cl}
\hline \hline Polymorphism & \multicolumn{1}{c}{ PCR primers } \\
\hline IL1B rs16944 & $\begin{array}{l}\text { Forward, 5'TGGCATTGATCTGGTTCATC3' } \\
\text { Reverse, 5'GTTTAGGAATCTTCCCACTT3' }\end{array}$ \\
IL1B rs1143634 & Forward, 5'GTTGTCATCAGACTTTGACC3' \\
& Reverse, 5'TTCAGTTCATATGGACCAGA3' \\
IL6 rs1800795 & Forward, 5'GGAGTCACACACTCCACCT3' \\
& Reverse, 5'GTGGGGCTGATTGGAAACC3' \\
IL6 rs1800796 & Forward, 5'GAGAGGCCTTGAAGTAACTG3' \\
& Reverse, 5'AACCAAAGATGTTCTGAACTGA3' \\
IL10 rs1800896 & Forward, 5'GTAAGCTTCTGTGGCTGGAGT3' \\
& Reverse, 5'TTTCCAGATATCTGAAGAAGTCCTG3' \\
IL18 rs187238 Forward, 5'TTGTAACATTGTAGGAATTACC3' & Reverse, 5'ATGTAATATCACTATTTTATGAGA3' \\
\hline
\end{tabular}

Table 2. Restriction enzymes used for genotyping of polymorphisms and the band sizes obtained on agarose gels

\begin{tabular}{|c|c|c|}
\hline Polymorphism & $\begin{array}{c}\text { Restriction } \\
\text { enzyme }\end{array}$ & Band(s) obtained on agarose \\
\hline \multirow[t]{3}{*}{ IL1B rs16944 } & AvaI & TT, 1 band (305 bp) \\
\hline & & TC, 3 bands (305 bp, $190 \mathrm{bp}$ and $115 \mathrm{bp})$ \\
\hline & & CC, 2 bands (190 bp and $115 \mathrm{bp}$ ) \\
\hline \multirow[t]{3}{*}{ IL1B rs1143634 } & TaqI & CC, 2 bands (136 bp and 114 bp) \\
\hline & & CT, 3 bands (250 bp, $136 \mathrm{bp}$ and $114 \mathrm{bp}$ ) \\
\hline & & $\mathrm{TT}, 1$ band (250 bp) \\
\hline \multirow[t]{3}{*}{ IL6 rs1800795 } & SfaNI & GG, 1 band (532 bp) \\
\hline & & GC, 3 bands (532 bp, $474 \mathrm{bp}$ and $58 \mathrm{bp}$ ) \\
\hline & & $\mathrm{CC}, 2$ bands (474 bp and $58 \mathrm{bp}$ ) \\
\hline \multirow[t]{3}{*}{ IL6 rs1800796 } & BsrBI & CC, 1 band (180 bp) \\
\hline & & CG, 3 bands (180 bp, $120 \mathrm{bp}$ and $60 \mathrm{bp}$ ) \\
\hline & & GG, 2 bands (120 bp and $60 \mathrm{bp}$ ) \\
\hline \multirow[t]{3}{*}{ IL10 rs1800896 } & MnlI & AA, 1 band $(130 \mathrm{bp})$ \\
\hline & & AG, 3 bands (130 bp, $100 \mathrm{bp}$ and $30 \mathrm{bp}$ ) \\
\hline & & GG, 2 bands (100 bp and $30 \mathrm{bp}$ ) \\
\hline \multirow[t]{3}{*}{ IL18 rs187238 } & EcoRI & GG, 2 bands (107 bp and 24 bp) \\
\hline & & GC, 3 bands (131 bp, $107 \mathrm{bp}$ and $24 \mathrm{bp}$ ) \\
\hline & & CC, 1 band (131 bp) \\
\hline
\end{tabular}


association analyses.

\section{RESULTS}

The attributes of the cases are shown in Table 3. The ages of both cases and controls ranged from 27-39 years, and mean ages were similar in both groups: $33.34 \pm 3.65$ years in cases and $33.17 \pm 3.76$ years in controls. Among the cases, $83(13.9 \%)$ were smokers. The prevalence was similar to the controls, of whom $72(11.9 \%)$ were smokers. With regard to alcohol consumption habits, 491 $(82.1 \%)$ cases and $509(84.4 \%)$ controls never drank or were occasional drinkers, in comparison with 93 (15.6\%) cases and $86(14.3 \%)$ who were regular drinkers and $14(2.3 \%)$ cases and $8(1.3 \%)$ controls who were heavy drinkers. Despite this, none of the subjects drank any alcohol during pregnancy. No significant difference was observed between cases and controls in age, smoking habits or alcohol consumption habits $(P>0.05$, Table 3$)$.

The distributions of $I L 1 B$ rs16944, IL1B rs1143634, IL6 rs1800795, IL6 rs1800796, IL10 rs1800896 and IL18 rs187238 polymorphisms are shown in Table 4. All polymorphisms conformed to Hardy-Weinberg equilibrium (Table 4), suggesting that the distribution was random and representative of the general population.

Odds ratios (ORs) were calculated to measure the association between the polymorphisms and risk of recurrent pregnancy loss. The results are shown in Table 5. Among the six polymorphisms, only $I L 1 B$ rs16944

Table 3. Attributes of cases and controls

\begin{tabular}{ccccc}
\hline \hline & Attribute & Cases & Controls & $P$ \\
\hline $\mathrm{N}$ & 598 & 603 & -
\end{tabular}

Age

Mean

Range

Smoking habit

Yes

No

Alcohol consumption

Never/occasional

Regular

Heavy

Alcohol consumption during pregnancy

Yes

No
0.4172

$33.34 \pm 3.65$

$$
\text { 27-39 }
$$

$33.17 \pm 3.76$

27-39

0.3162

$\begin{array}{rr}83(13.9 \%) & 72(11.9 \%) \\ 515(86.1 \%) & 531(88.1 \%)\end{array}$

0.3307

$\begin{array}{cc}491(82.1 \%) & 509(84.4 \%) \\ 93(15.6 \%) & 86(14.3 \%) \\ 14(2.3 \%) & 8(1.3 \%)\end{array}$

1.0000

$0(0.0 \%) \quad 0(0.0 \%)$

$598(100.0 \%) \quad 603(100.0 \%)$ and IL6 rs1800796 polymorphisms demonstrated a significant association with risk of recurrent pregnancy loss among our subjects when the $P$ value threshold was set at $<0.008$ following Bonferroni correction. The het-

Table 4. Distribution of polymorphisms and deviation from HWE

\begin{tabular}{|c|c|c|c|}
\hline Polymorphism & Cases & Controls & $\begin{array}{l}\text { Hardy-Weinberg } \\
P \text { value (control) }\end{array}$ \\
\hline$I L 1 B \operatorname{rs} 16944$ & & & 0.1568 \\
\hline $\mathrm{TT}$ & $155(25.9 \%)$ & $218(36.2 \%)$ & \\
\hline $\mathrm{TC}$ & $294(49.2 \%)$ & $275(45.6 \%)$ & \\
\hline $\mathrm{CC}$ & $149(24.9 \%)$ & $110(18.2 \%)$ & \\
\hline $\mathrm{T}$ & $604(50.5 \%)$ & $711(59.0 \%)$ & \\
\hline $\mathrm{C}$ & $592(49.5 \%)$ & $495(41.0 \%)$ & \\
\hline$I L 1 B \operatorname{rs} 1143634$ & & & 0.9296 \\
\hline $\mathrm{CC}$ & $482(80.6 \%)$ & $474(78.6 \%)$ & \\
\hline $\mathrm{CT}$ & $111(18.6 \%)$ & $121(20.1 \%)$ & \\
\hline $\mathrm{TT}$ & $5(0.8 \%)$ & $8(1.3 \%)$ & \\
\hline $\mathrm{C}$ & $1075(89.9 \%)$ & $1069(88.6 \%)$ & \\
\hline $\mathrm{T}$ & $121(10.1 \%)$ & $137(11.4 \%)$ & \\
\hline IL 6 rs1800795 & & & 0.4159 \\
\hline GG & $372(62.2 \%)$ & $369(61.2 \%)$ & \\
\hline GC & $197(32.9 \%)$ & $201(33.3 \%)$ & \\
\hline $\mathrm{CC}$ & $29(4.8 \%)$ & $33(5.5 \%)$ & \\
\hline G & $941(78.7 \%)$ & $939(77.9 \%)$ & \\
\hline $\mathrm{C}$ & $255(21.3 \%)$ & $267(22.1 \%)$ & \\
\hline IL 6 rs1800796 & & & 0.2401 \\
\hline $\mathrm{CC}$ & $435(72.7 \%)$ & $369(61.2 \%)$ & \\
\hline $\mathrm{CG}$ & $147(24.6 \%)$ & $199(33.0 \%)$ & \\
\hline GG & $16(2.7 \%)$ & $35(5.8 \%)$ & \\
\hline $\mathrm{C}$ & $1017(85.0 \%)$ & $937(78.1 \%)$ & \\
\hline G & $179(15.0 \%)$ & 269 (21.9\%) & \\
\hline IL10 rs1800896 & & & 0.2478 \\
\hline AA & $524(87.6 \%)$ & $512(84.9 \%)$ & \\
\hline AG & $70(11.7 \%)$ & $85(14.1 \%)$ & \\
\hline GG & $4(0.7 \%)$ & $6(1.0 \%)$ & \\
\hline $\mathrm{A}$ & $1118(93.5 \%)$ & $1109(92.0 \%)$ & \\
\hline G & $78(6.5 \%)$ & $97(8.0 \%)$ & \\
\hline IL18 rs187238 & & & 0.1430 \\
\hline GG & $458(76.6 \%)$ & $441(73.1 \%)$ & \\
\hline GC & $128(21.4 \%)$ & $144(23.9 \%)$ & \\
\hline $\mathrm{CC}$ & $12(2.0 \%)$ & $18(3.0 \%)$ & \\
\hline G & $1044(87.3 \%)$ & $1026(85.1 \%)$ & \\
\hline $\mathrm{C}$ & $152(12.7 \%)$ & $180(14.9 \%)$ & \\
\hline
\end{tabular}


Table 5. Odds ratios for the association with recurrent pregnancy loss risk

\begin{tabular}{|c|c|c|c|c|}
\hline Polymorphism & OR $(95 \% \mathrm{CI})$ & $P$ & Adjusted OR (95\% CI) & Adjusted $P$ \\
\hline \multicolumn{5}{|l|}{$I L 1 B$ rs16944 } \\
\hline $\mathrm{TT}$ & Ref & - & Ref & - \\
\hline $\mathrm{TC}$ & $1.5036(1.1553-1.9570)$ & 0.0024 & 1.4209 (1.1302-1.8929) & 0.0019 \\
\hline $\mathrm{CC}$ & $1.9051(1.3819-2.6265)$ & 0.0001 & $1.7398(1.2133-2.3203)$ & 0.0008 \\
\hline $\mathrm{T}$ & $\operatorname{Ref}$ & - & $\operatorname{Ref}$ & - \\
\hline $\mathrm{C}$ & $1.4078(1.1981-1.6542)$ & $<0.0001$ & $1.3747(1.1296-1.8972)$ & 0.0003 \\
\hline \multicolumn{5}{|l|}{$I L 1 B \operatorname{rs} 1143634$} \\
\hline $\mathrm{CC}$ & Ref & - & Ref & - \\
\hline CT & $0.9021(0.6770-1.2022)$ & 0.4820 & $0.9493(0.5393-1.7634)$ & 0.6753 \\
\hline $\mathrm{TT}$ & $0.6146(0.1996-1.8923)$ & 0.3962 & $0.7865(0.3302-2.3241)$ & 0.5031 \\
\hline $\mathrm{C}$ & $\operatorname{Ref}$ & - & Ref & - \\
\hline $\mathrm{T}$ & $0.8783(0.6780-1.1377)$ & 0.3256 & $0.8351(0.5354-1.3240)$ & 0.4623 \\
\hline \multicolumn{5}{|l|}{ IL6 rs1800795 } \\
\hline GG & Ref & - & Ref & - \\
\hline GC & $0.9722(0.7620-1.2404)$ & 0.8205 & $0.7524(0.5931-1.2012)$ & 0.7545 \\
\hline $\mathrm{CC}$ & $0.8717(0.5186-1.4651)$ & 0.6043 & $0.7440(0.4290-1.1354)$ & 0.5354 \\
\hline G & Ref & - & Ref & - \\
\hline $\mathrm{C}$ & $0.9530(0.7850-1.1570)$ & 0.6269 & $0.7435(0.4775-1.1467)$ & 0.6566 \\
\hline \multicolumn{5}{|l|}{ IL6 rs1800796 } \\
\hline $\mathrm{CC}$ & Ref & - & Ref & - \\
\hline CG & $0.6266(0.4859-0.8081)$ & 0.0003 & $0.7342(0.4412-0.8423)$ & 0.0016 \\
\hline GG & $0.3878(0.2112-0.7119)$ & 0.0022 & $0.5424(0.1768-0.7865)$ & 0.0014 \\
\hline $\mathrm{C}$ & $\operatorname{Ref}$ & - & $\operatorname{Ref}$ & - \\
\hline $\mathrm{G}$ & $0.6131(0.4975-0.7555)$ & $<0.0001$ & $0.7009(0.4511-0.8034)$ & 0.0007 \\
\hline \multicolumn{5}{|l|}{ IL10 rs1800896 } \\
\hline $\mathrm{AA}$ & Ref & - & Ref & - \\
\hline $\mathrm{AG}$ & $0.8047(0.5733-1.1294)$ & 0.2089 & $0.7431(0.3243-1.4289)$ & 0.3546 \\
\hline GG & $0.6514(0.1827-2.3219)$ & 0.5086 & $0.6680(0.3012-1.4901)$ & 0.5475 \\
\hline A & Ref & - & Ref & - \\
\hline G & $0.7977(0.5854-1.0869)$ & 0.1521 & $0.6952(0.5340-1.3948)$ & 0.4359 \\
\hline \multicolumn{5}{|l|}{ IL18 rs187238 } \\
\hline GG & Ref & - & Ref & - \\
\hline GC & $0.8559(0.6523-1.1230)$ & 0.2615 & $0.6289(0.5434-1.1396)$ & 0.6444 \\
\hline $\mathrm{CC}$ & $0.6419(0.3056-1.3482)$ & 0.2417 & $0.5333(0.3524-1.2043)$ & 0.4309 \\
\hline G & Ref & - & Ref & - \\
\hline $\mathrm{C}$ & $0.8299(0.6577-1.0471)$ & 0.1159 & $0.6027(0.4359-1.3435)$ & 0.3082 \\
\hline
\end{tabular}

erozygous TC genotype of $I L 1 B$ rs16944 polymorphism was found to contribute to a higher risk of recurrent pregnancy loss, with OR 1.5036 (1.1553-1.9570) $(P=$ 0.0024). Similarly, for the homozygous CC genotype, an increased risk was observed, with OR 1.9051 (1.38192.6265) $(P=0.0001)$. With the above observation, it is not surprising that the $\mathrm{C}$ allele also increased recurrent pregnancy loss risk, with OR 1.4078 (1.1981-1.6542) $(P<0.0001)$. After adjusting for clinical attributes of the subjects (age, smoking habits and alcohol consumption habits), all the genotypes and the allele were still significantly associated with increased risk for recurrent 
pregnancy loss. The heterozygous TC genotype reported an OR of $1.4209(1.1302-1.8929)(P=0.0019)$. In comparison, the homozygous CC genotype increased the risk with OR $1.7398(1.2133-2.3203)(P=0.0008)$. For the $\mathrm{C}$ allele, an OR of $1.3747(1.1296-1.8972)(P=0.0003)$ was seen.

On the contrary, the $I L 6$ rs 1800796 variant was significantly associated with a decreased risk of recurrent pregnancy loss. The heterozygous CG genotype had an OR of $0.6266(0.4859-0.8081)(P=0.0003)$ and an adjusted OR of $0.7342(0.4412-0.8423)(P=0.0016)$, while the homozygous GG genotype had an OR of $0.3878(0.2112-0.7119)$ $(P=0.0022)$ and an adjusted OR of $0.5424(0.1768$ 0.7865) $(P=0.0014)$. The $\mathrm{G}$ allele was also found to contribute to a decreased recurrent pregnancy loss risk, with OR $0.6131(0.4975-0.7555)(P<0.0001)$ and adjusted OR $0.7009(0.4511-0.8034)(P=0.0007)$.

\section{DISCUSSION}

In this work, we investigated the association of six interleukin gene polymorphisms with the risk of recurrent pregnancy loss. We observed a significant relationship for only two polymorphisms. First, the $I L 1 B$ rs16944 variant was found to be significantly associated with an increased risk of recurrent pregnancy loss. This polymorphism is caused by a T-to-C substitution at the -511 position of the gene promoter. For this reason, the rs16944 polymorphism has been shown to affect the expression of the $I L 1 B$ gene. However, contradictory findings have been observed with regard to whether the polymorphism increases or decreases $I L 1 B$ expression (Hwang et al., 2002; Iacoviello et al., 2005), although it has been shown that the cis-acting effect of the IL1B $-31 \mathrm{~T} / 511 \mathrm{C}$ haplotype is associated with increased expression compared with the $-31 \mathrm{C} /-511 \mathrm{~T}$ haplotype (Kimura et al., 2004). Nevertheless, we postulate that if the expression of the gene is not maintained at an optimum level, it poses a risk for pregnancy loss. Thus, the expression of the gene must be kept at a well-regulated level.

Our finding that the rs16944 variant was associated with an increased recurrent pregnancy loss risk was in agreement with some previous work (Kim et al., 2014; Ma et al., 2017), although other studies have reported no association between the polymorphism and recurrent pregnancy loss risk (Linjawi et al., 2005; Ma et al., 2012). This inconsistency may be due to the different study sizes employed. Our results agreed with those of two studies with larger sample sizes (Kim et al., 2014; Ma et al., 2017), but disagreed with two studies with smaller sample sizes (Linjawi et al., 2005; Ma et al., 2012). The study by Kim et al. (2014) comprised 385 cases and 232 controls and noted an OR of $1.826(1.130-2.953)$ for the variant genotype. Besides, the study by Ma et al. (2017) comprised 775 cases and 805 controls and showed that the variant genotype had an OR of 1.377 (1.039-1.824). In comparison, Linjawi et al. (2005) analyzed only 206 cases and 224 controls, while Ma et al. (2012) studied the polymorphism in 162 cases and 156 controls. No significant association was observed for the two latter studies. Studies involving a lower sample size may generate false-negative results, as their power may not be sufficient to detect the presence of a true association.

As well as the rs16944 polymorphism, we also studied the $I L 1 B$ rs 1143634 polymorphism. We found no association between this polymorphism and the risk of recurrent pregnancy loss. rs1143634 is caused by a C-to-T substitution that may affect the splicing of the transcript (Woods et al., 2015). Our results suggest that the splicing event plays no significant role in recurrent pregnancy loss. To date, two previous studies have investigated the association between the rs1143634 polymorphism and recurrent pregnancy loss risk (Ma et al., 2012, 2017). Both studies were conducted in Chinese populations. Taking together the results from this and previous work, we conclude that the rs1143634 polymorphism is not an important factor in recurrent pregnancy loss.

We also investigated two polymorphisms in the IL6 gene, whose product plays a role in embryonic implantation and placental development (Prins et al., 2012). We examined the rs1800795 and rs1800796 polymorphisms in our study. Both polymorphisms are located in the promoter region of the gene, which could influence the gene's expression. The rs1800795 polymorphism was not found to be associated with recurrent pregnancy loss, but the rs1800796 polymorphism was found to protect against recurrent pregnancy loss. Similar to the IL1B polymorphism, our observations on the rs1800795 and rs1800796 polymorphisms agreed with some previous findings and disagreed with others. For rs1800795, two previous studies observed a significant association with an increased recurrent pregnancy loss risk, with OR = 3.57 (Demirturk et al., 2014) and 1.78 (Parveen et al., 2013), while four previous studies did not (Alkhuriji et al., 2013; Bahadori et al., 2014; Bohiltea and Radoi, 2014; Ma et al., 2017). For rs1800796, the majority of previous studies reported findings similar to ours (Karhukorpi et al., 2001; Qaddourah et al., 2014; Ma et al., 2017), although one study failed to find an association between the polymorphism and risk of recurrent pregnancy loss (Alkhuriji et al., 2013). The inconsistency among study findings could be attributed to two reasons. First, as discussed above, lower sample sizes may not have sufficient power to detect an association (or lack thereof). Most of the studies above used only a small sample size: 38 cases for Karhukorpi et al. (2001), 65 for Alkhuriji et al. (2013), 69 for Bohiltea and Radoi (2014), 85 for Bahadori et al. (2014), 113 for Demirturk et al. (2014) and 296 for Qaddourah et al. (2014). Second, the population from 
which the subjects were recruited may also affect the results obtained, as differences in the genetic background of different ethnic groups could result in different findings due to high variability in allele frequency among different ethnicities (Dias and Ribeiro, 2011). This may explain why our findings generally concurred with $\mathrm{Ma}$ et al. (2017), who also investigated a few overlapping polymorphisms in a Chinese population.

Two other interleukin polymorphisms were investigated in this work, namely IL10 rs1800896 and IL18 rs187238. Both polymorphisms are located in the promoter region of the gene. We found no association between either polymorphism and the risk of recurrent pregnancy loss. The association between IL10 rs1800896 and recurrent pregnancy loss risk has been investigated since 2001, when a lack of association was observed (Karhukorpi et al., 2001). Several replicative studies that followed also found no association between the polymorphism and risk of recurrent pregnancy loss (Kamali-Sarvestani et al., 2005; Alkhuriji et al., 2013; Qaddourah et al., 2014; Ma et al., 2017), although two others did show an association (Parveen et al., 2013; Bahadori et al., 2014). Similarly, for the IL18 rs187238 polymorphism, our results concurred with three previous reports (Ostojić et al., 2007; Al-Khateeb et al., 2011; Messaoudi et al., 2012), but not with two others that showed a significant association (Wang et al., 2014; Yue et al., 2015). As discussed above, the inconsistency in study results may be due to study size or to genetic and/ or geographical features of the population from which the subjects were recruited.

In conclusion, this study demonstrated that IL1B rs16944 and IL6 rs1800796 variants were associated with an increased and a decreased recurrent pregnancy loss risk, respectively. A limitation of the current work is that no replication/validation set of samples was included. Future studies in the Chinese population will be required to replicate our work.

\section{REFERENCES}

Agrawal, S., Parveen, F., Faridi, R. M., and Prakash, S. (2012) Interleukin-1 gene cluster variants and recurrent pregnancy loss among North Indian women: retrospective study and meta-analysis. Reprod. Biomed. Online 24, 342-351.

Al-Khateeb, G. M., Sater, M. S., Finan, R. R., Mustafa, F. E., AlBusaidi, A. S., Al-Sulaiti, M. A., and Almawi, W. Y. (2011) Analysis of interleukin-18 promoter polymorphisms and changes in interleukin-18 serum levels underscores the involvement of interleukin-18 in recurrent spontaneous miscarriage. Fertil. Steril. 96, 921-926.

Alkhuriji, A. F., Alhimaidi, A. R., Babay, Z. A., and Wary, A. S. (2013) The relationship between cytokine gene polymorphism and unexplained recurrent spontaneous abortion in Saudi females. Saudi Med. J. 34, 484-489.

Bahadori, M., Zarei, S., Zarnani, A. H., Zarei, O., Idali, F., Hadavi, R., and Jeddi-Tehrani, M. (2014) IL-6, IL-10 and IL-17 gene polymorphisms in Iranian women with recurrent miscarriage. Iran. J. Immunol. 11, 97-104.

Bohiltea, C. L., and Radoi, V. E. (2014) Interleukin-6 and interleukin-10 gene polymorphisms and recurrent pregnancy loss in Romanian population. Iran. J. Reprod. Med. 12, 617-622.

Chen, H., Yang, X., Du, J., and Lu, M. (2015) Interleukin-18 gene polymorphisms and risk of recurrent pregnancy loss: a systematic review and meta-analysis. J. Obstet. Gynaecol. Res. 41, 1506-1513.

Cheng, S. B., and Sharma, S. (2015) Interleukin-10: a pleiotropic regulator in pregnancy. Am. J. Reprod. Immunol. 73, 487-500.

Daher, S., Mattar, R., Gueuvoghlanian-Silva, B. Y., and Torloni, M. R. (2012) Genetic polymorphisms and recurrent spontaneous abortions: an overview of current knowledge. Am. J. Reprod. Immunol. 67, 341-347.

Demirturk, F., Ates, O., Gunal, O., Bozkurt, N., Aysal, T., and Nacar, M. C. (2014) IL-6 gene promoter polymorphisms: genetic susceptibility to recurrent pregnancy loss. Bratisl. Lek. Listy. 115, 479-482.

Dias, V., and Ribeiro, V. (2011) Ethnic differences in the prevalence of polymorphisms in CYP7A1, CYP7B1 AND CYP27A1 enzymes involved in cholesterol metabolism. J. Pharm. Bioallied Sci. 3, 453-459.

Diejomaoh, M. F. E. (2015) Recurrent spontaneous miscarriage is still a challenging diagnostic and therapeutic quagmire. Med. Princ. Pract. 24, 38-55.

Garrido-Gimenez, C., and Alijotas-Reig, J. (2015) Recurrent miscarriage: causes, evaluation and management. Postgrad. Med. J. 91, 151-162.

Hwang, I. R., Kodama, T., Kikuchi, S., Sakai, K., Peterson, L. E., Graham, D. Y., and Yamaoka, Y. (2002) Effect of interleukin 1 polymorphisms on gastric mucosal interleukin $1 \beta$ production in Helicobacter pylori infection. Gastroenterology 123, 1793-1803.

Iacoviello, L., Di Castelnuovo, A., Gattone, M., Pezzini, A., Assanelli, D., Lorenzet, R., Del Zotto, E., Colombo, M., Napoleone, E., Amore, C., et al. (2005) Polymorphisms of the interleukin-1 $\beta$ gene affect the risk of myocardial infarction and ischemic stroke at young age and the response of mononuclear cells to stimulation in vitro. Arterioscler. Thromb. Vasc. Biol. 25, 222-227.

Kamali-Sarvestani, E., Zolghadri, J., Gharesi-Fard, B., and Sarvari, J. (2005) Cytokine gene polymorphisms and susceptibility to recurrent pregnancy loss in Iranian women. J. Reprod. Immunol. 65, 171-178.

Karhukorpi, J., Laitinen, T., Karttunen, R., and Tiilikainen, A. S. (2001) The functionally important IL-10 promoter polymorphism $(-1082 \mathrm{G} \rightarrow \mathrm{A})$ is not a major genetic regulator in recurrent spontaneous abortions. Mol. Hum. Reprod. 7, 201-203.

Kim, J. O., Lee, W. S., Lee, B. E., Jeon, Y. J., Kim, Y. R., Jung, S. H., Chang, S. W., and Kim, N. K. (2014) Interleukin-1beta $-511 \mathrm{~T}>\mathrm{C}$ genetic variant contributes to recurrent pregnancy loss risk and peripheral natural killer cell proportion. Fertil. Steril. 102, 206-212.

Kimura, R., Nishioka, T., Soemantri, A., and Ishida, T. (2004) Cis-acting effect of the $I L 1 B$ C-31T polymorphism on IL-1 $\beta$ mRNA expression. Genes Immun. 5, 572-575.

Lee, Y. H., Choi, S. J., and Ji, J. D. (2015) Association between $I L-6-174 \mathrm{G} / \mathrm{C}, I L-6-634 \mathrm{G} / \mathrm{C}$, and $I F N-\gamma+874 \mathrm{~A} / \mathrm{T}$ polymorphisms and susceptibility to recurrent pregnancy loss: a meta-analysis. J. Assist. Reprod. Genet. 32, 1421-1427.

Linjawi, S., Li, T. C., Laird, S., and Blakemore, A. (2005) Inter- 
leukin-1 receptor antagonist and interleukin-1 beta polymorphisms in women with recurrent miscarriage. Fertil. Steril. 83, 1549-1552.

Ma, J., Zhang, X., He, G., and Yang, C. (2017) Association between $T N F, I L 1 B, I L 6, I L 10$ and IFNG polymorphisms and recurrent miscarriage: a case control study. Reprod. Biol. Endocrinol. 15, 83.

Ma, X., Xu, L. J., Wang, J., Xian, M. M., and Liu, M. (2012) Association of $I L-1 \beta$ and $I L-6$ gene polymorphisms with recurrent spontaneous abortion in a Chinese Han population. Int. J. Immunogenet. 39, 15-19.

Messaoudi, S., Dandana, M., Magdoud, K., Meddeb, S., Ben Slama, N., Hizem, S., and Mahjoub, T. (2012) Interleukin-18 promoter polymorphisms and risk of idiopathic recurrent pregnancy loss in a Tunisian population. J. Reprod. Immunol. 93, 109-113.

Ostojić, S., Volk, M., Medica, I., Kapović, M., Meden-Vrtovec, H., and Peterlin, B. (2007) Polymorphisms in the interleukin-12/18 genes and recurrent spontaneous abortion. Am. J. Reprod. Immunol. 58, 403-408.

Parveen, F., Shukla, A., and Agarwal, S. (2013) Cytokine gene polymorphisms in northern Indian women with recurrent miscarriages. Fertil. Steril. 99, 433-440.

Prins, J. R., Gomez-Lopez, N., and Robertson, S. A. (2012) Interleukin-6 in pregnancy and gestational disorders. J. Reprod. Immunol. 95, 1-14.

Qaddourah, R. H., Magdoud, K., Saldanha, F. L., Mahmood, N., Mustafa, F. E., Mahjoub, T., and Almawi, W. Y. (2014) IL-10 gene promoter and intron polymorphisms and changes in IL-10 secretion in women with idiopathic recurrent miscarriage. Hum. Reprod. 29, 1025-1034.
Southcombe, J. H., Redman, C. W. G., Sargent, I. L., and Granne, I. (2015) Interleukin-1 family cytokines and their regulatory proteins in normal pregnancy and pre-eclampsia. Clin. Exp. Immunol. 181, 480-490.

Su, D., Zhang, Y., Wang, Q., Wang, J., Jiao, B., Wang, G., and $\mathrm{Wu}, \mathrm{X}$. (2016) Association of interleukin-10 gene promoter polymorphisms with recurrent miscarriage: a metaanalysis. Am. J. Reprod. Immunol. 76, 172-180.

Sykes, L., MacIntyre, D. A., Yap, X. J., Teoh, T. G., and Bennett, P. R. (2012) The Th1:Th2 dichotomy of pregnancy and preterm labour. Mediators Inflamm. 2012, 967629.

Thaxton, J. E., and Sharma, S. (2010) Interleukin-10: a multifaceted agent of pregnancy. Am. J. Reprod. Immunol. 63, 482-491.

Wang, D., Wang, C., Zheng, L. Z., Zhu, M., and Zhu, Y. M. (2014) Relationship between IL-18 gene polymorphism and unexplained recurrent spontaneous abortion. Zhejiang Da Xue Xue Bao Yi Xue Ban 43, 448-452 (in Chinese).

Weissenbacher, E. R., Wirth, M., Mylonas, I., Ledger, W. J., and Witkin, S. S. (2014) Immunology of the Female Genital Tract. Springer, Heidelberg.

Woods, N. T., Monteiro, A. N., Thompson, Z. J., Amankwah, E. K., Naas, N., Haura, E. B., Beg, A., and Schabath, M. B. (2015) Interleukin polymorphisms associated with overall survival, disease-free survival, and recurrence in non-small cell lung cancer patients. Mol. Carcinog. 54, E172-E184.

Yue, J., Tong, Y., Zhou, J., Liu, Q., and Yang, J. (2015) Genetic variant in interleukin-18 is associated with idiopathic recurrent miscarriage in Chinese Han population. Int. J. Mol. Sci. 16, 4180-4189. 